Acta Crystallographica Section A

\section{Foundations of Crystallography}

ISSN 0108-7673

\section{book reviews}

Works intended for this column should be sent direct to the Book-Review Editor, whose address appears in this issue. All reviews are also available from Crystallography Journals Online, supplemented where possible with direct links to the publisher's information.
Theories and techniques of crystal structure determination. By Uri Shmueli, Pp. 269. Oxford: Oxford University Press, 2007. Price GBP 32.50. ISBN 978-0-19-921350-4.

When I learnt ahead of its publication that Uri Shmueli was writing a textbook on crystal structure determination, two thoughts occurred to me. One was that the author was certain to do an excellent job, the other however was that there seemed little justification for yet another entrant on this particular crowded scene. However, after reading his book, I perceive it has qualities which set it apart from the pack, so to speak, and it is on those features that I shall concentrate.

There was a time when it was the norm for crystallographers to undergo a long practical training, an apprenticeship as it were, at an established laboratory, before going out to further spread the gospel elsewhere. The basic theory of our science came as a standard library of eight or ten classic texts - any crystallographer of my generation knows the ones I mean, and will recognize them all in Shmueli's bibliography - but the practical details were held as secrets of the craft. All this changed about the time Stout \& Jensen published the first edition of their text [Stout, G. H. \& Jensen, L. H. (1968) X-ray Structure Determination: a Practical Guide. London: Macmillan], as their subtitle a Practical Guide and their stated intention to record the 'folklore of crystallography', made abundantly clear. The new order considered crystal structure analysis simply a technique, where 'service' crystallographers could set up in isolation, making use of standard methodology expert systems, or 'black boxes' to the reactionary!

This book is called Theories and Techniques of Crystal Structure Analysis, but it would perhaps be more aptly titled Theories and the Theories behind the Techniques, since throughout it maintains - or even exceeds - the level of abstraction of the old-style texts I mentioned above. Indeed, it forms a classical education in X-ray crystallography, presented with rigour and austerity, but using mathematics within the reach of students of all backgrounds. (Although students coming to it from chemistry or biology might find the paucity of actual referent structures somewhat disconcerting!)

The text consists of ten chapters, followed by four significant Appendices explaining the mathematical background to various topics. The first three chapters discuss the geometric foundations of crystallography, leading up to an enumeration of the space groups, and a survey of the information available in International Tables for Crystallography. Chapter 4 describes the diffraction conditions, the production of X-rays and the methods of recording the diffraction pattern. The next four chapters together cover the crystallographic phase problem and its solution, by dealing in turn with the topics of structure factor and electron density, the Patterson function, structure-factor statistics and direct methods. Chapter 9 discusses the various ways of modelling atomic displacement parameters, a necessary precursor to the final chapter on the theory of least-squares refinement. Each of these chapters is followed by a number of exercises closely tied - sometimes even essential - to the text material.

The text is well presented save for a few misprints scattered through Chapter 8, suggesting perhaps that particular material was just too familiar to the author. The use of figures is frugal and there is but a single plate, but their use is in the main well judged and in keeping with the general approach of treating general theory rather than exemplars. However, I feel that occasionally the opportunity to present a commonly applied visualization was missed; I would have liked to see an example of a contoured Fourier or Patterson section, and a section of the diffraction pattern displayed as a weighted reciprocal net.

On the other hand, the real strength of this book lies in the way it condenses and modernizes the material of the classic texts I mentioned before, and so should take their place on the young crystallographer's bookshelf. Its excellent bibliography readily provides for further exploration of the discipline. In fact, my hope for this text is that it will lead a new generation to take a closer look at the fundamentals of crystallography, whether that simply means they gain a sounder grounding for their work, that they are encouraged to review and improve the computer systems we all now use, or that they actually undertake fundamental research in crystallography, an area which, despite the efforts of the recently formed Commission on Mathematical and Theoretical Crystallography, continues to decline in published output.

\section{John S. Rutherford}

1 Barliath

Minard

Argyll

PA32 8YQ

Scotland

E-mail: john.rutherford@btinternet.com 